OPEN ACCESS

Edited by:

Hui Yao,

Beijing University of Technology,

China

Reviewed by:

Jiaqing Wang,

Nanjing Forestry University, China

Kim S. Siow,

National University of Malaysia,

Malaysia

*Correspondence:

Sebastian Dahle

sebastian.dahle@bf.uni-lj.si

Specialty section: This article was submitted to

Structural Materials,

a section of the journal

Frontiers in Materials

Received: 16 October 2021 Accepted: 15 December 2021

Published: 17 January 2022

Citation:

Dahle S, Srinivasa K, Žigon J, Cheumani Yona AM, Avramidis G, Viöl W and Petrič M (2022) Influence of

Air Plasma Pretreatments on

Mechanical Properties in Metal-

Reinforced Laminated Wood.

Front. Mater. 8:796474.

doi: 10.3389/fmats.2021.796474

\section{Influence of Air Plasma Pretreatments on Mechanical Properties in Metal-Reinforced Laminated Wood}

\author{
Sebastian Dahle ${ }^{1 *}$, Kavyashree Srinivasa ${ }^{1}$, Jure Žigon ${ }^{1}$, Arnaud Maxime Cheumani Yona ${ }^{1,2}$, \\ Georg Avramidis ${ }^{3}$, Wolfgang Viöl ${ }^{3}$ and Marko Petrič ${ }^{1}$ \\ ${ }^{1}$ Department of Wood Science and Technology, Biotechnical Faculty, University of Ljubljana, Ljubljana, Slovenia, \\ ${ }^{2}$ Macromolecular Research Team, Faculty of Science, University of Yaoundé, Yaoundé, Cameroon, ${ }^{3}$ Faculty of Engineering and \\ Health, HAWK University of Applied Sciences and Arts, Göttingen, Germany
}

The use of wood-based materials in building and construction is constantly increasing as environmental aspects and sustainability gain importance. For structural applications, however, there are many examples where hybrid material systems are needed to fulfil the specific mechanical requirements of the individual application. In particular, metal reinforcements are a common solution to enhance the mechanical properties of a wooden structural element. Metal-reinforced wood components further help to reduce cross-sectional sizes of load-bearing structures, improve the attachment of masonry or other materials, enhance the seismic safety and tremor dissipation capacity, as well as the durability of the structural elements in highly humid environments and under high permanent mechanical load. A critical factor to achieve these benefits, however, is the mechanical joint between the different material classes, namely the wood and metal parts. Currently, this joint is formed using epoxy or polyurethane (PU) adhesives, the former yielding highest mechanical strengths, whereas the latter presents a compromise between mechanical and economical constraints. Regarding sustainability and economic viability, the utilization of different adhesive systems would be preferable, whereas mechanical stabilities yielded for metal-wood joints do not permit for the use of other common adhesive systems in such structural applications. This study extends previous research on the use of non-thermal air plasma pretreatments for the formation of wood-metal joints. The plasma treatments of Norway spruce [Picea abies (L.) Karst.] wood and anodized (E6/ EV1) aluminum AlMgSi0.5 (6060) F22 were optimized, using water contact angle measurements to determine the effect and homogeneity of plasma treatments. The adhesive bond strengths of plasma-pretreated and untreated specimens were tested with commercial 2-component epoxy, PU, melamine-urea formaldehyde (MUF), polyvinyl acetate (PVAc), and construction adhesive glue systems. The influence of plasma treatments on the mechanical performance of the compounds was evaluated for one selected glue system via bending strength tests. The impact of the hybrid interface between metal and wood was isolated for the tests by using five-layer laminates from three wood lamellae enclosing two aluminum plates, thereby excluding the influence of congeneric wood-wood bonds. The effect of the plasma treatments is discussed based on 
the chemical and physical modifications of the substrates and the respective interaction mechanisms with the glue systems.

Keywords: non-thermal plasma, spruce, aluminum, metal-reinforced laminate, shear strength, bending strength

\section{INTRODUCTION}

Wood is one of the most important and most widely used renewable materials in construction, building and furniture applications. Many applications utilize solid wood components, glue-laminated semi-finished products (including plywood, laminated veneer lumber and glulam components) or wood-polymer composites (such as fiberboards, particleboards or oriented strain boards) (Tang et al., 2005; Zhang et al., 2019). An increasing number of applications, however, require enhanced mechanical strength, reduced cross-sections of load-bearing elements, or increased aspect ratios of constructive components. A possible way to achieve these requirements is by combining metal and wood into hybrid materials, e.g., by reinforcement of wooden components with metal bars, nets or plates (Soriano et al., 2016; Uzel et al., 2018), but also other materials such as fibre-reinforced polymers were tested as reinforcements for wood components (De Vecchi et al., 2008). Particularly metal-wood composites most commonly utilize steel or aluminum as reinforcing elements. The stiffness and strength obtainable with the hybrid material, however, are often limited by the adhesion strength between lamination elements from the different materials classes (Steiger et al., 2006; Jasieńko and Nowak 2014). The employed adhesive systems most commonly include phenol-resorcinol, epoxy and PU adhesives (Tlustochowicz et al., 2011; Uzel et al., 2018). Nevertheless, many parameters impact the joint's mechanical performance, including the compatibility of both materials with the adhesive system, surface roughness, geometry of the joint and bond line thickness (Chans et al., 2013; Budhe et al., 2015; Azinović et al., 2018; Peng and Zhang 2018). Hence, it is crucial to select an appropriate surface modification technique to yield a well-performing joint (Williams et al., 2014; Da Ponte et al., 2015).

The preparation of surfaces for the joint formation can be carried out using different mechanical, chemical or physical methods that modify the substrate's surface morphology and chemistry (Sauerbier et al., 2018; Nečasová et al., 2019). Among them, plasma treatments $(\mathrm{PT})$ are a type of fast and versatile physical methods, which do not require organic solvents and are thus more environmentally friendly than many conventional methods (Lecoq et al., 2008). Plasma technology is well known in many academic fields and industrial sectors (Hippler 2001; Wagner et al., 2003). The plasma modification typically affects surfaces within depth of several $100 \AA$ into solid materials (Joshi and Butola 2013; Peng and Zhang 2018) to several $100 \mathrm{~nm}$ for (porous) wood (Král et al., 2015), but the bulk properties usually remain unchanged (Chu et al., 2002; Recek 2019). Depending on the substrate material, the effect of a PT can fade over time. While it typically is persistent over a long time on aluminum, it will typically only last several days or weeks on wooden substrates due to migration of mobile wood components (e.g., extractives) (c.f.
Talviste et al., 2019). A very common form of technical plasma is the dielectric barrier discharge (DBD), where an insulating barrier between two electrodes prevents the formation of an arc (Brandt et al., 2016) and hence ensures temperatures at typically no more than $10 \mathrm{~K}$ above room temperature for this form of non-thermal plasma (Kogelschatz 2003). Many scientific studies use DBDs for cleaning and activation of metal, polymeric or wooden surfaces, e.g., for the improvement of adhesive bond strengths (Bour et al., 2008; Lahmar et al., 1995; Tang et al., 2005; Tang et al., 2006; Zhang et al., 2019; Zhang et al., 2020). This effect is yielded in air plasmas through the generation of oxygencontaining groups, such as hydroxyl, carbonyl or carboxyl groups (Gramlich et al., 2006; Tang et al., 2005, Tang et al., 2006; Nguyen et al., 2018). Due to the polar character of most of these oxygen-containing groups, the plasma functionalization typically yields a strong increase of the polar component of the surface free energy (SFE), i.e., increasing the hydrophilicity (Sauerbier et al., 2018).

The treatment of metals with non-thermal plasmas was utilized for a number of applications. Most commonly, steel is used as electrode material in DBD ozone generators (Kogelschatz 2000). DBD air plasmas in particular are an effective means for degreasing metal surfaces, e.g., on iron (Baravian et al., 1999) or aluminum (Klingner et al., 2013). In contrast to that, other gases such as Argon, Helium, or forming gas mixtures are more common for metal surface activation and for producing advanced functionalities (Goossens et al., 2001). Such PT of metals are commonly utilized in industrial sectors including e.g., automotive or electronics manufacturing (Kim et al., 2003). A typical application of atmospheric plasmas on metal in the different fields is the improvement of adhesion strength, e.g., the pull-off strength of silicone rubber coatings (Latifi et al., 2014), PU(Gähde et al., 1992), poly (pyromelliticdianhydride-co4,4 V-oxydianiline)amic acid based adhesives (Tang et al., 2006), epoxy adhesives (Williams et al., 2014) and many others. The improvement of the adhesion strengths is typically yielded through both, cleaning (e.g., degreasing) and functionalization, such as the formation of $-\mathrm{OH}$ groups or carboxylic acid $(-\mathrm{COOH})$ groups (Lee et al., 2009; Williams et al., 2014). Similarly, aluminum was found to form higher adhesion strengths with glues and coatings through PT (Critchlow and Brewis 1996; Mui et al., 2017). Further, the natural 2-3 nm oxide layer of aluminum is extended through atmospheric PT, thus further improving its corrosion resistance ( $\mathrm{Li}$ and Wang 2009).

Application of DBD plasmas to wood is much more challenging than to conventional substrates, due to the nonhomogenous nature of this natural polymer (Levasseur et al., 2014). Many different atmospheric plasmas were utilized for different applications on wood and other lignocellulosic materials (Žigon et al., 2018). Using air plasmas mostly yields a functionalization via oxidation, yielding hydroxyl, methoxy, 
carbonyl and carboxyl groups that are formed mainly on lignin, but to a smaller degree also on cellulose and hemicellulose (Klarhöfer et al., 2010). Due to the complexity of both systems, plasma and wood, proper treatment parameters need to be found for every new application case (Tang et al., 2006; Peng and Zhang 2019; Talviste et al., 2019).

In a previous study (Žigon et al., 2020), we investigated the use of air PT for joining beech wood with aluminum and steel using epoxy, PU, melamine urea-formaldehyde (MUF) and polyvinyl acetate (PVAc) adhesives. On steel, the plasma pretreatments slightly increased the roughness through corrosion processes, whereas no difference in roughness was visible on neither aluminum nor wood. All three substrates exhibited additional functional groups (e.g., $-\mathrm{OH}, \mathrm{C}=\mathrm{O}$ ) after the air PT and the SFE increased on all three substrates, accordingly. More particularly, the polar component increased on all three substrates, whereas the dispersive component of the SFE increased on wood and steel, but slightly decreased on aluminum. The wood-wood joints exhibited a lower adhesion strength after PT for epoxy and PU adhesives, but an increased adhesion strength for MUF and PVAc. The wood-steel joints showed an increase of adhesion strength for the plasma pretreated samples for all adhesives and particularly noteworthy was the results that PVAc after PT exceeded all untreated joints, including epoxy and PU. For wood-aluminum joints, PT yielded an increase of adhesion strengths for all adhesives, as well, but most pronounced improvements were yielded for PVAc and MUF glue, with the PVAc joint after plasma pretreatment outperforming all other wood-aluminum joints, including epoxy and PU after plasma pretreatment.

In the present research, we look into an extended use of an atmospheric DBD plasma as a surface preparation technique enhancing the bonding strength for wood-metal hybrid composites. This is investigated with regards to structural elements, where spruce wood and aluminum reinforcements are most commonly used. Air PT are optimized using water contact angles, as the most indicative part of the SFE regarding the effect of plasma pretreatments. Adhesive bond strengths are investigated for epoxy and PU adhesives, which are the industrial state of the art for these composites, for PVAc and MUF, which are typical economic and more environmentally friendly wood glues, as well as for construction adhesive, which is often utilized in building applications. The most promising adhesives are further investigated for mechanical stability in bending strength tests, which more directly represents the typical loading that occurs in structural applications. For these tests, five-layer laminates (wood-aluminum-wood-aluminum-wood) are utilized instead of more complex three-dimensional parts with fully embedded metal reinforcements, such that the impact of the PT on the wood-metal joint can be directly deduced without impacts by additional wood-wood joints.

\section{MATERIALS AND METHODS}

\subsection{Substrate Preparation}

Norway spruce (Picea abies (L.) Karst.) wood and anodized (E6/ EV1) aluminum AlMgSi0.5 (6060) F22 materials were used as substrates. The spruce wood was sawn from sapwood into lamellae with a thickness of $5 \mathrm{~mm}$ and radial orientation of the grain. Aluminum specimen were sawn from flat bar material with $2 \mathrm{~mm}$ thickness. For both, wood and aluminum, equally sized specimen were prepared in three different sizes as follow:

- $30 \mathrm{~mm} \times 30 \mathrm{~mm}$ for water contact angle (WCA) measurements and optimization of PT,

- $50 \mathrm{~mm} \times 30 \mathrm{~mm}$ for preparation of lap joints and testing of shear strength, and

- $420 \mathrm{~mm} \times 30 \mathrm{~mm}$ for preparation of laminated stacks and testing of bending strength.

Prior to PT and the formation of adhesive joints, all aluminum specimens were cleaned by wiping with ethanol ( $>97 \%)$, whereas the wood specimens were equilibrated in the laboratory with a residual moisture content of approx. $10.3 \%$ as determined gravitationally after the DIN EN 13183-1:2002-07 standard (Beuth Verlag GmbH, 2002).

\subsection{Water Contact Angles (WCA)}

WCA were utilized as indicator for the impact of PT, which is a common way to optimize plasma treatment parameters for various applications (Altgen et al., 2020). An optical goniometer Theta (Biolin Scientific Oy, Espoo, Finland) was used together with its corresponding software (OneAttension version 2.4 [r4931], Biolin Scientific, Oy, Espoo, Finland) to measure the WCA by tangent fitting the shape of a $3 \mu \mathrm{L}$ droplet. WCAs were recorded for $60 \mathrm{~s}$ after the initial contact of the droplet with the sample surface and all original measured data are provided in the published dataset. On every aluminum specimen, at least 5 different spots were measured. On every wood specimen, at least 10 spots were measured, out of which at least 5 measurements were conducted for each direction of observation, i.e., parallel and perpendicular to the grain. Analyzed data presented and discussed below take the average of measured angles on both sides of the droplets for all specimens of equal type after a setting time of $5 \mathrm{~s}$ after initial contact between droplet and sample surface.

\subsection{Plasma Device}

A simple DBD setup was used, consisting of a $70 \mathrm{~cm} \times 50 \mathrm{~cm}$ moving table with a height-adjustable portal (Dahle et al., 2021a), into which the plasma device and power supply were integrated. Both directions of movement of table and portal are controlled using a computer numerical control (CNC) setup consisting of four NEMA17 stepper motors, an Arduino Uno with the Protoneer CNC shield v3.0, and a Raspberry Pi 4 with original 7" touchscreen display, using the CNC.js (https:// github.com/cncjs/cncjs) software on a standard Raspbian operating system. The setup is displayed in Figure 1A. The step sizes were set to $0.47 \mu \mathrm{m}(2133$ steps $/ \mathrm{mm})$ for the placement of the electrode (i.e., height) and $10 \mu \mathrm{m}(100 \mathrm{steps} / \mathrm{mm})$ for the movement of the table. The practical accuracy in positioning and movement speed, however, amounts to approx. $0.1 \mathrm{~mm}$ due to construction choices. All settings of the CNC stage can be 


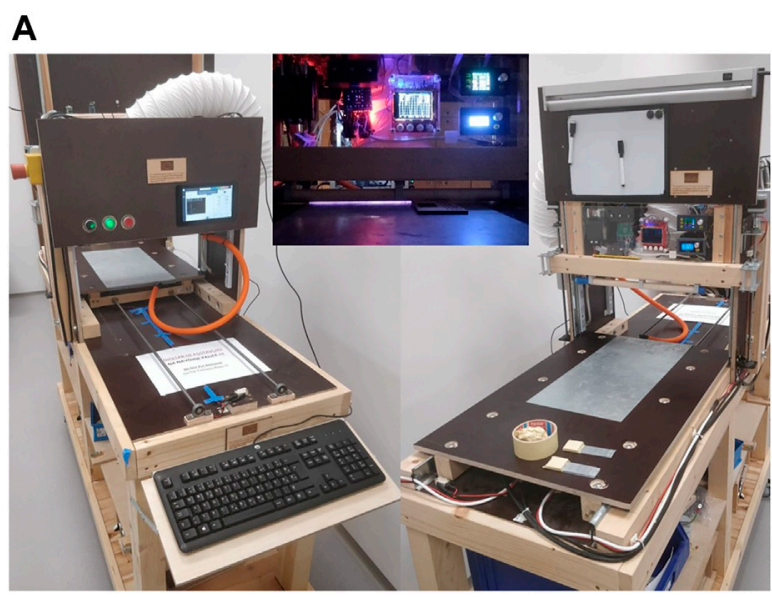

\section{B}

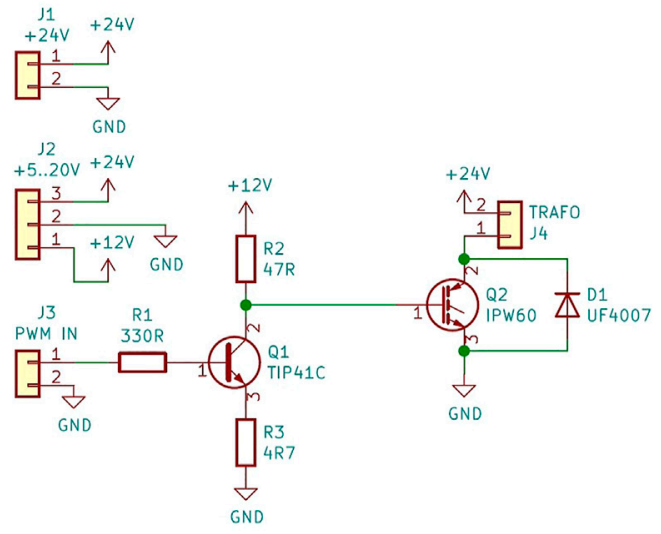

FIGURE 1 | Overall plasma setup (A) and electrical circuitry of the included HV power supply (B).

found along with the construction data in the publications dataset (Dahle et al., 2021a).

The dielectrically insulated high voltage (HV) electrode consisted of a $40 \mathrm{~cm}$ alumina tube with $15 \mathrm{~mm}$ outer diameter and $2.5 \mathrm{~mm}$ wall thickness (Degussit AL23, EXW Friatec AG, Mannheim, Germany) filled with copper wire wool (pot cleaner) sealed with silicone gasket material (Soudal Gasket Seal, Soudal N.V., Leverkusen, Germany). A $0.5 \mathrm{~mm}$ thick galvanized plain steel sheet (No. 465858, GAH Alberts, Gust. Alberts GmbH \& Co. $\mathrm{KG}$, Herscheid, Germany) covering the moving table used as grounded electrode. The HV was produced via a Flyback transformer (TRANSHF_15KVAC, Voltagezone Electronics e.U., Graz, Austria) driven by a simple MOSFET stage (CoolTip v1.0.0; c.f. Dahle 2021b) using an pulse-width modulation signal generator (XY-LPWM, Eshinede Technology, Shenzhen, China), a DPS5020 voltage regulator (HangZhou RuiDeng Technologies, Shenzhen, China), an ATX power supply (MPII550, Mars Gaming, Biomag, Vitoria-Gasteiz, Spain) and a step-up module $(1500 \mathrm{~W}, 30 \mathrm{~A}$ boost converter, Walfront, China) together with a self-holding contactor latch for safe operation. Further, a DSO138mini oscilloscope (JYE Tech Ltd., Guangxi, China) was included for online diagnostics. The schematic of the HV power supply is displayed in Figure 1B.

All mechanical constructions, wiring diagrams, circuitry schematics, and PCB designs including GERBER files are openly available within the publication's dataset at Zenodo (Dahle et al., 2021a).

\subsection{Plasma Treatments}

$\mathrm{PT}$ were carried out as single-sided direct DBD treatments for shear strength and WCA measurements, whereas both sides of specimens were treated for bending strength tests. The HV power supply was operated at $20 \mathrm{~V}, 5 \mathrm{kHz}$, and $87 \%$ duty cycle (i.e., $26 \mu$ s of current flow through transformer primary side followed by $174 \mu$ s without current flow), yielding a sinoidal HV output waveform (c.f. Mahdavipour et al., 2019). The power supply is equipped for max. $300 \mathrm{~W}$ power throughput, whereas the overall power consumptions of the device during the plasma treatments in this study typically amount to $150 \mathrm{~W}$. Surfaces of aluminum specimens were treated once with $\mathrm{d}=(1 \pm 0.1) \mathrm{mm}$ gap distance and $1 \mathrm{~mm} /$ $s$ forwarding speed, whereas wood specimens were treated twice at the same parameters, thus yield a total exposure time of $2 \mathrm{~s}$ for wood and $1 \mathrm{~s}$ for aluminum.

Typical properties of plasmas in similar applications were determined earlier to amount to a power density of $\mathrm{ca} .1 \mathrm{~W} / \mathrm{cm}^{2}$, depending on the substrate's properties (conductivity, dielectric permittivity) and particularly for wood on the species and moisture content (Dahle et al., 2015; Peters et al., 2017; Dahle et al., 2020). Typical translational, rotational and vibrational gas temperatures in similar discharges are in the order of magnitude of $300 \mathrm{~K}, 400 \mathrm{~K}$, and $2500 \mathrm{~K}$, respectively, while mean electron energies typically fall in the range of 8-9 eV (Dahle et al., 2015; Peters et al., 2017).

Optimized recipes are provided as G codes in the article's dataset at Zenodo (Dahle et al., 2021a).

\subsection{Adhesive Joint Formation}

\subsubsection{Glue-Up for Shear Strength Testing}

Adhesive joints for shear strength testing were formed in batches of 20 specimens with equal numbers of specimens formed from untreated materials and specimens formed from plasmapretreated spruce and plasma-pretreated aluminum (i.e., 10 untreated, 10 plasma-pretreated). Individual lap joints were obtained by a $1 \mathrm{~cm}$ overlap of the $3 \mathrm{~cm}$ wide substrates, thus forming a bonding area of $3 \mathrm{~cm}^{2}$ for each specimen. The following adhesive systems were utilized according to the manufacturers' respective instructions:

1. PVAc fast-setting dispersion adhesive Mekol ekspress (Mitol d.o.o., Sežana, Slovenia), held to cure at room temperature in a hydraulic press at 8 bar for $15 \mathrm{~min}$,

2. MUF adhesive Meldur H97 (Melamin d.d., Kočevje, Slovenia) with 33 wt.-\% formic acid initiator for cold-curing (TRDILEC M-L3,0, Melamin d.d., Kočevje, Slovenia), held to cure at room temperature in a hydraulic press at 8 bar for $240 \mathrm{~min}$, 


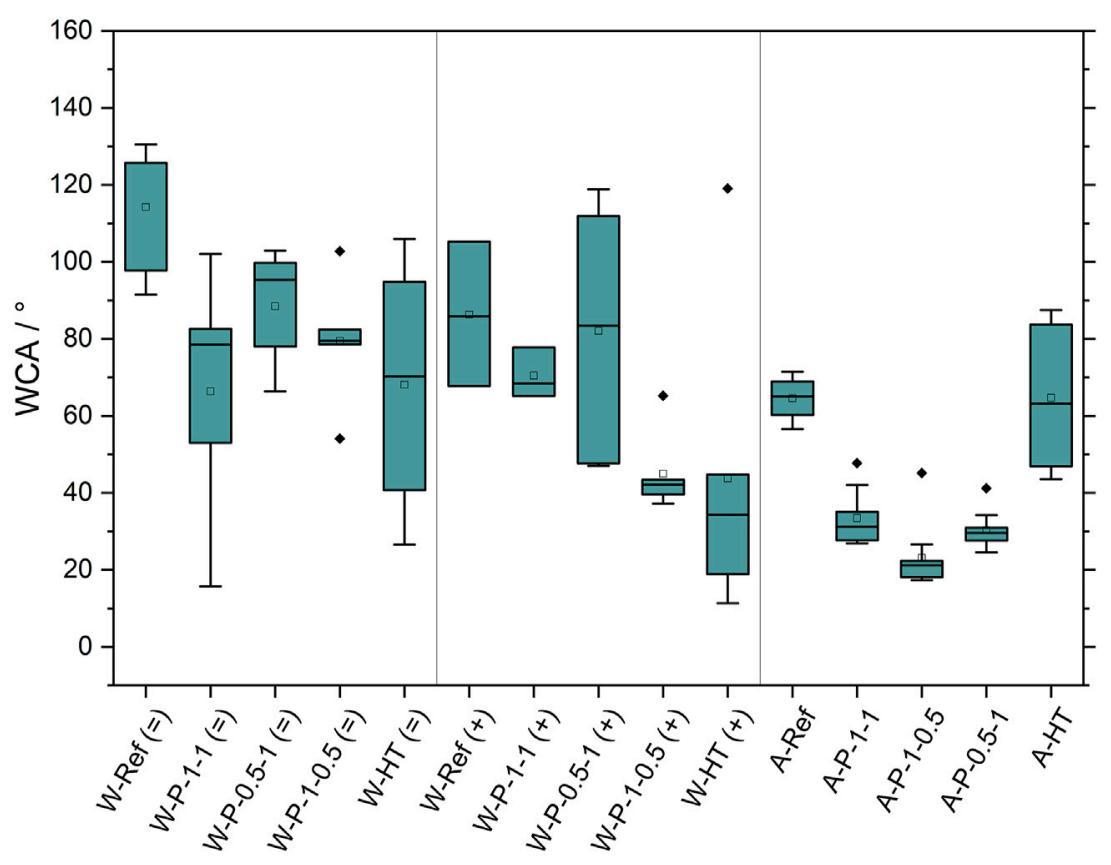

FIGURE 2 | Water contact angle (WCA) results for different sample systems denominated by Material (Wood; Aluminum)-Treatment (Untreated Reference; Plasma; Homogeneity Test) - Gap distance in mm-Forwarding speed in mm/s, and observation direction (=) parallel to the grain or (+) perpendicular to the grain, respectively.

3. 1-component PU adhesive Mitopur E45 (Mitol d. o.o., Sežana, Slovenia), held to cure at room temperature in a hydraulic press at 8 bar for $20 \mathrm{~min}$,

4. 1-component construction adhesive (CoA) Mitomont HP50 (Mekol d.o.o., Sežana, Slovenia), cured without external pressure at room temperature, and

5. 2-component epoxy (EPO) UHU plus endfest, epoxy ultra strong (UHU GmbH \& Co. KG, Bühl, Germany), cured without external pressure at room temperature.

All specimens were kept for an additional $72 \mathrm{~h}$ at room temperature and a humidity of $50 \%$ to complete curing prior to mechanical testing. Any excess glue around the bonding area was cut off the sides or down to the substrate using a utility knife for PVAc, MUF and PU, or a hacksaw for CoA and EPO, thereby avoiding impact of spill-outs onto the results of the mechanical tests.

\subsubsection{Glue-Up for Bending Strength Testing}

Specimens for bending strength tests were fabricated as stacks of 5 sheets of alternating material with 3 spruce lamellae being separated by 2 aluminum sheets. Wood lamellae were aligned for alternating wood grain orientation. Batches of specimens with four stacks of sheets, each, were pressed simultaneously at room temperature in three different conditions for different batches: at 8 bar for $15 \mathrm{~min}$, at $2 \mathrm{bar}$ for $15 \mathrm{~min}$ and at 2 bar for $30 \mathrm{~min}$, respectively. Statistical analyses were performed and evaluated with a confidence coefficient of $95 \%$ according to the procedure after Dunnett (1955).

\subsection{Adhesion Strength Testing}

The tensile shear strength testing was performed on ten specimens per series using a universal testing machine Z005 (ZwickRoell, Ulm, Germany) according to the protocol after the ISO EN 4587:1995 standard (International Organization for Standardization, 1995). After the end of the test, the failure type was evaluated visually. The bending strength tests were conducted according to the DIN EN 310:1993-08 stanard (Beuth Verlag GmbH, 1993), with dimensional specifications in accordance also with the definitions by the ISO EN 130614:2014 standard (International Organization for Standardization, 2014) and the DIN EN 14374:2004 standard (Beuth Verlag $\mathrm{GmbH}$, 2004), and with the lower support points as roller placed $38 \mathrm{~cm}$ apart. Statistical analyses were performed and evaluated with a confidence coefficient of 95\% according to the procedure after Dunnett (1955), using the tabled critical values from Dunnett (1964).

\section{RESULTS}

\subsection{Water Contact Angles and Plasma Optimization}

Figure 2 shows WCA measurements for spruce wood (W) and aluminum (A) specimens. The results are displayed in three sets, namely the wood specimens as observed parallel to the grain $(=)$, the wood specimens observed perpendicular to the grain $(+)$ and the aluminum specimens. Within each set, a non-treated reference sample is compared to samples plasma treated at $1 \mathrm{~mm}$ gap distance and $1 \mathrm{~mm} / \mathrm{s}$ forwarding speed $(\mathrm{P}-1-1)$, 


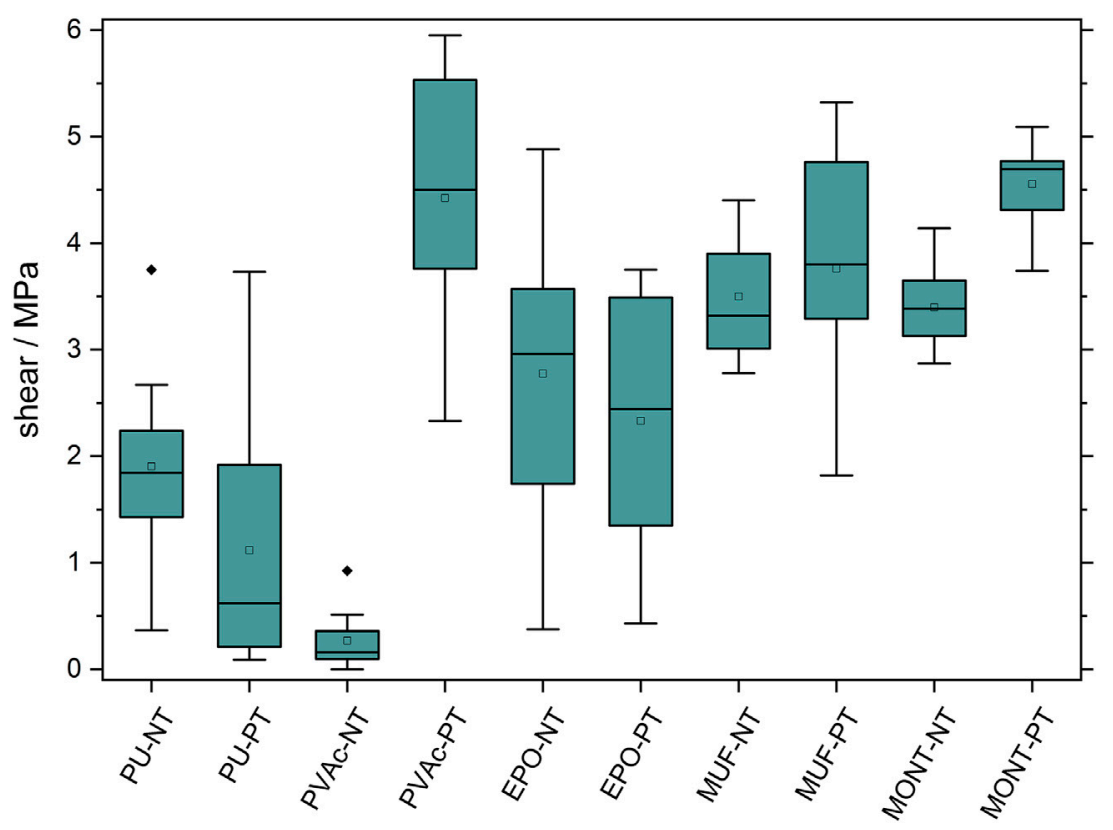

FIGURE 3 |Adhesive shear strength results for plasma-treated (PT) and not treated (NT) spruce and aluminum lamellae using polyurethane (PU), polyvinyl acetate (PVAc), epoxy (EPO), melamine urea-formaldehyde (MUF) and construction adhesive (MONT).

$0.5 \mathrm{~mm}$ gap and $1 \mathrm{~mm} / \mathrm{s}$ speed (P-0.5-1), as well as $1 \mathrm{~mm}$ gap and $0.5 \mathrm{~mm} / \mathrm{s}$ speed (P-1-0.5), which results in a total plasma exposition time of approx. 1 and $2 \mathrm{~s}$, respectively. Finally a homogeneity test was conducted for the simultaneous PT of 6 specimens located along the electrode (-HT). On every specimen, at least 10 individual WCA measurements were conducted. In Figure 2 the small square marks indicate the statistical average WCA value, the colored box diagrams enclose the $25-75 \%$ medians, and the metering lines indicate 1.5 IQR (interquartile range), whereas outliers are marked by black diamonds.

On the spruce wood specimens, the line of sight of the camera in parallel with the grain $(=)$ yields overall higher WCAs as well as higher deviations/IQR due to the grain boundaries limiting the spread of the droplet in the plane of observation. However, trends are consistent between both directions of observation. Gap distances of 1 and $0.5 \mathrm{~mm}$ appear to results in similar outcomes, whereas $0.5 \mathrm{~mm}$ starts to bring about alignment issues with the slightest twisting or cupping of lamellae. Results in the target range of WCA below $40^{\circ}$ are obtained for $2 \mathrm{~s}$ treatments, i.e., two repetitions of treatments at a forward speed of $1 \mathrm{~mm} / \mathrm{s}$. The homogeneity test with six specimens spread along the entire span of the electrode consistently reproduces the results of previous sets of treatment, albeit with slightly increased deviations due to the lower number of specimens. It can be concluded, though, from both visual observation as well as the contact angles on the specimens from different locations on the device that the PT is performing reasonably homogeneously for parallel treatments without limitations.

On the aluminum specimens, the WCAs only marginally decreased both by reducing the gap width from $1 \mathrm{~mm}$ down to $0.5 \mathrm{~mm}$ as well as by increasing the treatment time from $1 \mathrm{~s}$ up to $2 \mathrm{~s}$. This indicates an optimum condition for the easier to set up $1 \mathrm{~mm}$ gap width and a single treatment at a speed of $1 \mathrm{~mm} / \mathrm{s}$. The homogeneity test visually revealed uneven plasma ignition particularly for positions furthest from the connection cable contacting the HV electrode. This is reflected by much higher WCAs from those positions and accordingly by higher average WCAs, standard deviations, and interquartile ranges for the heterogeneity test. Consequently, all further plasma treatments were carried out with no more than 2 samples close together and located nearby the HV contact, in order to ensure a homogeneous and reproducible result of the PT.

\subsection{Influence of Plasma on Shear Strength}

Figure 3 shows the results of the adhesive shear strength tests for joints of spruce and aluminum lamellae using polyurethane (PU), polyvinyl acetate (PVAc), epoxy (EPO), melamine ureaformaldehyde (MUF) and construction adhesive (MONT). Sets of specimens with both substrates pretreated in a DBD plasma (PT) are compared to reference specimens without surface pretreatment (NT). The specimens prepared with PU adhesive exhibited a decrease of $41 \%$ maximum shear stress on the plasma-treated samples as compared with the untreated specimens. Moreover, a strong increase of statistical deviation is visible, such that the difference between plasma-treated and untreated specimens amounts to only $80 \%$ of the standard deviation. For the PVAc adhesive, plasma pretreatments yielded an increase of maximum shear stress by a factor of 15.4. The statistical variation of values increased for the PT specimens, as well, but the resulting shear strength values are statistically significant with a change in value of more than $5.7 \times$ the standard deviation and more than $3 \times$ the interquartile range. 


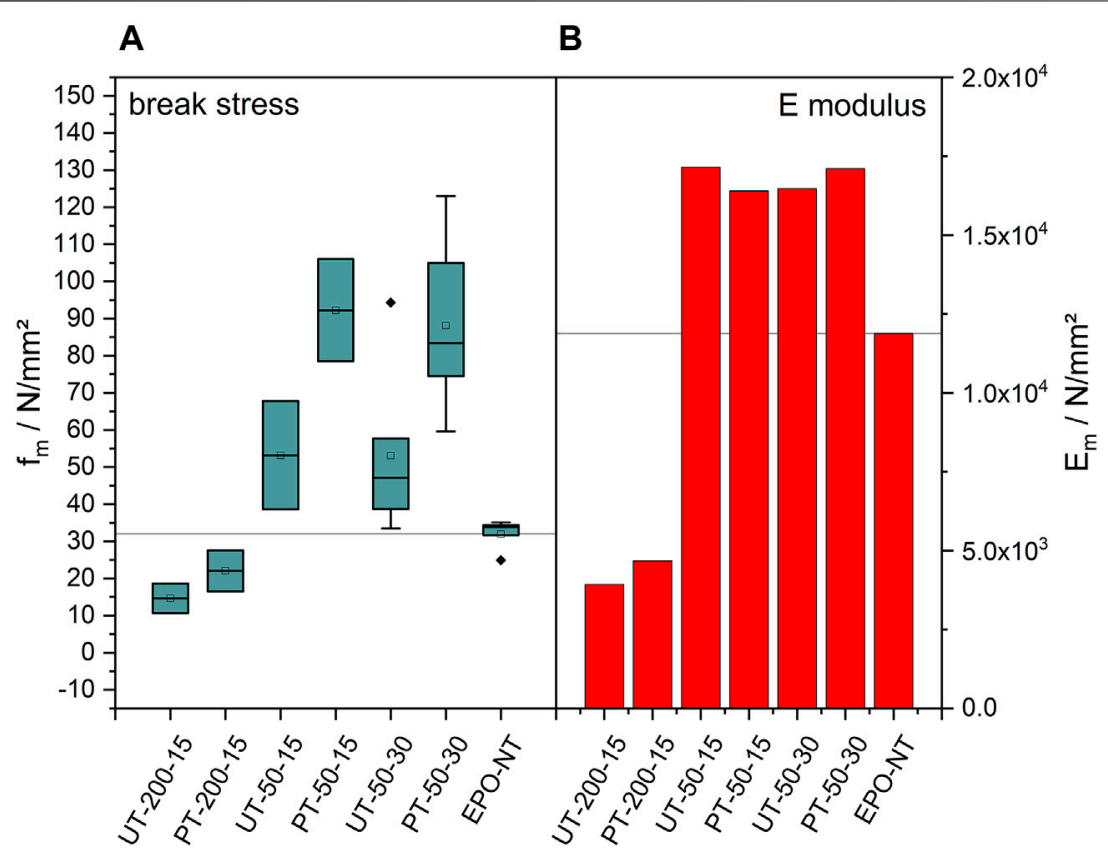

FIGURE 4 | Maximum break stress (A) and determined E modulus (B) from bending strength testing for spruce-aluminum composites with PVAc adhesive with plasma (PT) and without pretreatment (UT) cured in a hydraulic press at 8 bar for 15 min (200-15), 2 bar for 15 min (50-15) and at 2 bar for 30 min (50-30), as well as for reference specimens prepared without plasma and press using epoxy adhesive.

The epoxy adhesive did not show a significant change by plasma pretreatments. The averaged value on PT specimens was $16 \%$ lower compared to the untreated specimens, which amounts to only $34 \%$ of the standard deviation and ca. $30 \%$ of the interquartile range. The MUF adhesive exhibited an $8 \%$ increase of shear strength for the plasma-treated specimens as compared to the untreated ones. With only $29 \%$ of the standard deviation and ca. $1 / 3^{\text {rd }}$ of the interquartile range, this constitutes no statistically significant impact of the PT. The construction adhesive yielded a $34 \%$ higher shear strength for the plasma-pretreated specimens over the untreated substrates. This exceeds $3 \times$ the standard deviation and the averaged values are well outside of their mutual 1.5 IQR range. In comparison of the different adhesive systems, it is noteworthy that the PVAc adhesive without plasma pretreatment represented the worst performance of all sample systems, but with plasma pretreatment outperformed all other adhesive joints. This is highlighted in the evaluation after Dunnett (1955) with a confidence coefficient of 0.95 confirming an increased shear strength by at least a factor $\times 11$.

\subsection{Influence of Plasma on Bending Strength}

Figure 4 shows results of bending strength tests for five layer spruce-aluminum composites with PVAc adhesive both, with plasma (PT) and without pretreatment (UT). PVAc composites were cured in a hydraulic press at 8 bar for $15 \mathrm{~min}$ (200-15), 2 bar for $15 \mathrm{~min}(50-15)$ and at 2 bar for $30 \mathrm{~min}$ (50-30).
Further reference specimens were prepared without plasma and press using EPOadhesive, as this is the de-facto industry standard for these types of mixed-material composites. The maximum break stress results (left) and the determined modulus of elasticity (E modulus, right) are therefore presented in front of a line representing the average value obtained for EPOto ease the comparison with the current use practice. At 8 bar holding pressure, damages to the wood lamellae visually impacted the mechanical integrity of the specimens, which is represented by an overall $\mathrm{E}$ modulus and a maximum break stress of only approx. $1 / 3^{\text {rd }}$ of the epoxy specimens. Holding times of $15 \mathrm{~min}$ as indicated by the manufacturer of the adhesive led to a partial opening of the glue joint and a formation of visual gaps along the bond line. This was not the case for a doubled holding time of $30 \mathrm{~min}$, which yielded homogenous and visually defect-free joints. These observations, however, are not reflected in the break stress or $\mathrm{E}$ modulus, as for both parameters no differences were measured for different holding times at 2 bar holding pressure. Plasma pretreatments yielded an average increase of ca. $160 \%$ of the maximum break stress and an average increase of ca. $110 \%$ of the $\mathrm{E}$ modulus compared to the corresponding untreated specimens. In comparison to the EPO reference, the plasmapretreated specimens produced with PVAc adhesive exhibit on average a ca. $40 \%$ higher E modulus and approx. 2.8 times the maximum break stress, whereas statistical evaluations according to Dunnett (1955) with a confidence coefficient of 0.95 yield an increased $\mathrm{E}$ modulus and maximum break stress of at least $18 \%$ and factor 2, respectively. Moreover, the plasma pretreatment led to an increased dilation until break by a factor of 2 . 


\section{DISCUSSION}

The plasma treatments were effectively implemented using an open and available technology that is accessible to small laboratories and private individuals, thus opening up this technology for broader and more widespread utilization. The WCA results indicate an effective pretreatment of the specimens. In particular, the aluminum samples well reproduce previous results indicating mainly a degreasing, but also a likely extension of the natural oxide layer thickness and a minor complexation of the oxide surface (c.f. Žigon et al., 2020; Klingner et al., 2013). The spruce samples reproduce other results that indicate a removal of grease and extractives from the outer surfaces as well as a formation of polar groups, such as hydroxyl, methoxy, carbonyl and carboxyl groups (Žigon et al., 2018).

The shear strengths results confirm an improved bond strength of the joint particularly for those adhesives that interact with polar surface components, such as PVAc and construction adhesive, as opposed to MUF, PU and EPOadhesives. This well corresponds to an earlier study particularly for PVAc and beech wood (Žigon et al., 2020), thereby transferring these results from hardwood to softwood. Moreover, the strong improvement of the adhesion strength of construction adhesive through plasma pretreatments in contrast to a negative result of PU adhesive is noteworthy, since the main constituent of construction adhesives is PU. This highlights the relevance of additives and fillers for the interaction of adhesives with the surfaces of different materials. Further, this indicates the need for additional studies towards a variety of applications for surface preparation techniques in general and plasma treatments in particular.

The bending tests yielded results that differed quite substantially from the shear strength tests' results. An increased holding pressure during the curing of the PVAc adhesive led to structural damages in the wood lamellae, which are represented by significantly reduced $\mathrm{E}$ modulus and maximum break stress. However, PVAc joints even without PT, which exhibited the adhesion strength in shear tests, show higher E modulus and break stress in bending tests than those with the EPO adhesive. The PT led to an improved performance that is consistent with the improvement observed in the shear strength tests. However, no quantitative differences were observed neither for maximum break stress nor for $\mathrm{E}$ modulus of those samples with visible defects or gaps in the bond line. This clearly shows that different ways of evaluating and testing adhesive joints cannot directly be compared, i.e., directly inferring from one load type or application to another is not justified.

\section{CONCLUSION}

The use of DBD plasma pretreatments in air have been successfully utilized on spruce wood and aluminum metal work pieces. The optimized plasma pretreatments yielded improved shear strengths particularly for PVAc and construction adhesive, but did not create a significant change for EPO, PU, or MUF adhesives. Particularly the PVAc adhesive in combination with plasma pretreatments outperformed the EPOadhesive, which is the current de-facto industry standard for metal-wood joints. The bending strengths of 5-layer composites of spruce wood and aluminum with PVAc adhesives increased by a factor of 2.6 with twice the dilation until break and an approx. doubled $\mathrm{E}$ modulus for plasma pretreated specimens, thus again outperforming the EPO adhesives by factors of 2.8 and 1.4 for break stress and $\mathrm{E}$ modulus, respectively. This constitutes a promising result for all structural applications using wood-metal composite materials, indicating that the use of plasma allows for significantly higher loads while using a more economic and more environmentally friendly adhesive.

\section{DATA AVAILABILITY STATEMENT}

The datasets presented in this study can be found in online repositories. The names of the repository/repositories and accession number(s) can be found below: https://doi.org/10. 5281/zenodo.5572757.

\section{AUTHOR CONTRIBUTIONS}

SD: Conceptualization, Methodology, Formal analysis, Investigation, Data Curation, Writing-Original Draft, Visualization, Supervision, Project administration. KS: Conceptualization, Formal analysis, Investigation, Writing-Review and Editing. JŽ: Conceptualization, Resources, Writing-Review and Editing. AY: Investigation, Writing-Review and Editing. GA: Writing-Review and Editing. WV: Writing-Review and Editing, Funding acquisition. MP: Resources, Supervision, Writing-Review and Editing, Project administration, Funding acquisition.

\section{FUNDING}

This research has received financial support from the Slovenian Research Agency under research program funding No. P4-0015, "Wood and lignocellulose composites". This project has received funding from the European Union's Horizon 2020 research and innovation programme under grant agreement Nos 745936 and 867451. A CC BY or equivalent license is applied to the Author Accepted Manuscript arising from this submission, in accordance with the grant's open access conditions.

\section{ACKNOWLEDGMENTS}

The authors are thankful to Sergej Medved for the provision of the MUF adhesive as well as access to the Zwick universal testing machine. The authors acknowledge the financial support from the Slovenian Research Agency (research program funding No. P4-0015, "Wood and lignocellulose composites"). 


\section{REFERENCES}

Altgen, D., Altgen, M., Kyyrö, S., Rautkari, L., and Mai, C. (2020). Time-dependent Wettability Changes on Plasma-Treated Surfaces of Unmodified and Thermally Modified European Beech wood. Eur. J. Wood Prod. 78, 417-420. doi:10.1007/ s00107-020-01505-0

Azinović, B., Serrano, E., Kramar, M., and Pazlar, T. (2018). Experimental Investigation of the Axial Strength of Glued-In Rods in Cross Laminated Timber. Mater. Struct. 51, 143. doi:10.1617/s11527-018-1268-y

Baravian, G., Chaleix, D., Choquet, P., Nauche, P. L., Puech, V., and Rozoy, M. (1999). Oil Removal from Iron Surfaces by Atmospheric-Pressure Barrier Discharges. Surf. Coat. Technology 115 (1), 66-69. doi:10.1016/S02578972(99)00162-0

Beuth Verlag GmbH (2002). Moisture Content of a Piece of Sawn Timber - Part 1: Determination by Oven Dry Method. (DIN EN Standard No. 13183-1:2002-07). Berlin, Germany. Available at https://www.beuth.de/en/standard/din-en13183-1/43796306.

Beuth Verlag GmbH (2004). Timber Structures - Structural Laminated Veneer Lumber - Requirements. (DIN EN Standard No. 14374:2004). Berlin, Germany. Available at https://www.beuth.de/en/standard/din-en-14374/70543196.

Beuth Verlag GmbH (1993). Wood-Based Panels; Determination of Modulus of Elasticity in Bending and of Bending Strength. (DIN EN Standard No. 310:199308). Berlin, Germany. Available at https://www.beuth.de/en/standard/din-en310/1916935.

Bour, J., Bardon, J., Aubriet, H., Del Frari, D., Verheyde, B., Dams, R., et al. (2008). Different Ways to Plasma-Polymerize HMDSO in DBD Configuration at Atmospheric Pressure for Corrosion protection. Plasma Process. Polym. 5, 788-796. doi:10.1002/ppap.200800052

Brandt, S., Schütz, A., Klute, F. D., Kratzer, J., and Franzke, J. (2016). Dielectric Barrier Discharges Applied for Optical Spectrometry. Spectrochimica Acta B: At. Spectrosc. 123, 6-32. doi:10.1016/j.sab.2016.07.001

Budhe, S., Ghumatkar, A., Birajdar, N., and Banea, M. D. (2015). Effect of Surface Roughness Using Different Adherend Materials on the Adhesive Bond Strength. Appl. Adhes. Sci. 3 (1), 20. doi:10.1186/s40563-015-0050-4

Chans, D. O., Estévez Cimadevila, J., and Martín Gutiérrez, E. (2013). Withdrawal Strength of Threaded Steel Rods Glued with Epoxy in wood. Int. J. Adhes. Adhesives 44, 115-121. doi:10.1016/j.ijadhadh.2013.02.008

Chu, P. K., Chen, J. Y., Wang, L. P., and Huang, N. (2002). Plasma-surface Modification of Biomaterials. Mater. Sci. Eng. R. Rep. 36 (5), 143-206. doi:10.1016/S0927-796X(02)00004-9

Critchlow, G. W., and Brewis, D. M. (1996). Review of Surface Pretreatments for Aluminium Alloys. Int. J. Adhes. Adhesives 16, 255-275. doi:10.1016/S01437496(96)00014-0

Da Ponte, G., Ghosh, A. K., Kakaroglou, A., Van Hemelrijck, D., Van Mele, B., and Verheyde, B. (2015). Adhesion Improvement between Epoxy and Stainless Steel Using a Silane Coupling Agent in an Atmospheric Plasma Process. Plasma Process. Polym. 12, 347-361. doi:10.1002/ppap.201400106

Dahle, S. (2021b). SebastianDahle/PlasmaSolution: (V1.1.2). Zenodo. doi:10.5281/ zenodo. 5566469

Dahle, S., Srinivasa, K., Žigon, J., Yona, A. M. C., Avramidis, G., Viöl, W., et al. (2021a). Raw and Analyzed Data to Manuscript Influence of Air Plasma Pretreatments on Mechanical Properties in Metal-Reinforced Laminated wood. Zenodo. [Data set]. doi:10.5281/zenodo.5572757

Dahle, S., Hirschberg, J., Viöl, W., and Maus-Friedrichs, W. (2015). Gas Purification by the Plasma-Oxidation of a Rotating Sacrificial Electrode. Plasma Sourc. Sci. Technol. 24 (3), 035021. doi:10.1088/0963-0252/24/3/035021

Dahle, S., Žigon, J., Petrič, M., and Kariž, M. (2020). Plasma Treatment of spruce wood Changes its Dielectric Properties. Leswood 69 (2), 83-95. doi:10.26614/ les-wood.2020.v69n02a03

De Vecchi, A., Colajanni, S., Deletis, R., Catanese, A., and Iudicello, S. (2008). Reinforced Glulam: an Innovative Building Technology. Int. J. Housing Sci. 32 (3), 207-221.

Dunnett, C. W. (1955). A Multiple Comparison Procedure for Comparing Several Treatments with a Control. J. Am. Stat. Assoc. 50 (272), 1096-1121. doi:10.1080/01621459.1955.10501294

Dunnett, C. W. (1964). New Tables for Multiple Comparisons with a Control. Biometrics 20 (3), 482. doi:10.2307/2528490
Gähde, J., Friedrich, J. F., Gehrke, R., Loeschcke, I., and Sachse, J. (1992). Adhesion of Polyurethane to Surface-Modified Steel. J. Adhes. Sci. Technology 6 (5), 569-586. doi:10.1163/156856192X00403

Goossens, O., Dekempeneer, E., Vangeneugden, D., Van de Leest, R., and Leys, C. (2001). Application of Atmospheric Pressure Dielectric Barrier Discharges in Deposition, Cleaning and Activation. Surf. Coat. Technology 142-144, 474-481. doi:10.1016/S0257-8972(01)01140-9

Gramlich, W. M., Gardner, D. J., and Neivandt, D. J. (2006). Surface Treatments of wood-plastic Composites (WPCs) to Improve Adhesion. J. Adhes. Sci. Technology 20 (16), 1873-1887. doi:10.1163/156856106779116623

Hippler, R. (2001). Low Temperature Plasma Physics: Fundamental Aspects and Applications. 1st edn. Berlin: Wiley VCH. ISBN 978-3527288878.

International Organization for Standardization (1995). Adhesives Determination of Tensile Lap-Shear Strength of Rigid-to-Rigid Bonded Assemblies: (ISO Standard No. 4587:1995). Geneva, Switzerland: ISO. Available at https://www.iso.org/standard/22501.html.

International Organization for Standardization (2014). Physical and Mechanical Properties of Wood - Test Methods for Small Clear Wood Specimens - Part 4: Determination of Modulus of Elasticity in Static Bending. (ISO Standard No. 13061-4:2014). Geneva, Switzerland: ISO. Available at https://www.iso.org/ standard/60066.htm.

Jasieńko, J., and Nowak, T. P. (2014). Solid Timber Beams Strengthened with Steel Plates - Experimental Studies. Construction Building Mater. 63, 81-88. doi:10.1016/j.conbuildmat.2014.04.020

Joshi, M., and Butola, B. S. (2013). "Application Technologies for Coating, Lamination and Finishing of Technical Textiles,". Advances in the Dyeing and Finishing of Technical Textiles. Editor M. L. Gulrajani (New Delhi: Woodhead Publishing Series in Textiles), 355-411. ISBN 978-0-85709-433-9. doi:10.1533/9780857097613.2.355

Kim, M. C., Yang, S. H., Boo, J.-H., and Han, J. G. (2003). Surface Treatment of Metals Using an Atmospheric Pressure Plasma Jet and Their Surface Characteristics. Surf. Coat. Technology 174-175, 839-844. doi:10.1016/S0257-8972(03)00560-7

Klarhöfer, L., Viöl, W., and Maus-Friedrichs, W. (2010). Electron Spectroscopy on Plasma Treated Lignin and Cellulose. Holzforschung 64, 331-336. doi:10.1515/ hf. 2010.048

Klingner, S., Voigts, F., Viöl, W., and Maus-Friedrichs, W. (2013). Analysis of Plasma Degreased Aluminium Foil with XPS. Surf. Eng. 29 (5), 396-401. doi:10.1179/1743294413Y.0000000129

Kogelschatz, U. (2000). "Fundamentals and Applications of Dielectric-Barrier Discharges," in HAKONE VII, International Symposium on High Pressure, Low Temperature Plasma Chemistry, Greifswald, Germany, 1, 1-7.

Kogelschatz, U. (2003). Dielectric-Barrier Discharges: Their History, Discharge Physics, and Industrial Applications. Plasma Chem. Plasma Process. 23 (1), 1-46. doi:10.1023/A:1022470901385

Král, P., Ráhel, J., Stupavská, M., Šrajer, J., Klímek, P., Mishra, K. P., et al. (2015). XPS Depth Profile of Plasma-Activated Surface of Beech Wood (Fagus sylvatica) and Its Impact on Polyvinyl Acetate Tensile Shear Bond Strength. Wood Sci. Technol. 49, 319-330. doi:10.1007/s00226-014-0691-7

Lahmar, A., Scudeller, Y., Danes, F., and Bardon, J. P. (1995). X-ray Photoelectron Spectroscopy Analysis of thermal and Plasma-Treated Steel Substrates and Their Interface Formed with an Aluminium Layer. Thin Solid Films 266, 58-61. doi:10.1016/0040-6090(95)06646-2

Latifi, A., Imani, M., Khorasani, M. T., and Daliri Joupari, M. (2014). Plasma Surface Oxidation of 316L Stainless Steel for Improving Adhesion Strength of Silicone Rubber Coating to Metal Substrate. Appl. Surf. Sci. 320, 471-481. doi:10.1016/j.apsusc.2014.09.084

Lecoq, E., Clément, F., Panousis, E., Loiseau, J.-F., Held, B., Castetbon, A., et al. (2008). Pinus Pinaster Surface Treatment Realized in Spatial and Temporal Afterglow DBD Conditions. Eur. Phys. J. Appl. Phys. 42 (1), 47-53. doi:10.1051/ epjap:2008021

Lee, C. J., Lee, S. K., Ko, D. C., Kim, D. J., and Kim, B. M. (2009). Evaluation of Surface and Bonding Properties of Cold Rolled Steel Sheet Pretreated by Ar/O2 Atmospheric Pressure Plasma at Room Temperature. J. Mater. Process. Technology 209, 4769-4775. doi:10.1016/j.jmatprotec.2008.11.043

Levasseur, O., Bouarouri, A., Naude, N., Clergereaux, R., Gherardi, N., and Stafford, L. (2014). Organization of Dielectric Barrier Discharges in the Presence of Structurally Inhomogeneous Wood Substrates. IEEE Trans. Plasma Sci. 42 (10), 2366-2367. doi:10.1109/TPS.2014.2321518 
Li, Y., and Wang, L. (2009). Study of Oxidized Layer Formed on Aluminium alloy by Plasma Oxidation. Thin Solid Films 517, 3208-3210. doi:10.1016/ j.tsf.2008.10.098

Mahdavipour, B., Zaplotnik, R., Panjan, M., Oberrath, J., and Dahle, S. (2019). Impact of Gas Flow on Dielectric Barrier Discharge for Air Purification (1.0.2). 24th International Symposium on Plasma Chemistry (ISPC 24), Naples. Zenodo. doi:10.5281/zenodo.2634047

Mui, T. S. M., Silva, L. L. G., Prysiazhnyi, V., and Kostov, K. G. (2017). Surface Modification of Aluminium Alloys by Atmospheric Pressure Plasma Treatments for Enhancement of Their Adhesion Properties. Surf. Coat. Technology 312, 32-36. doi:10.1016/j.surfcoat.2016.08.024

Nečasová, B., Liška, P., Kelar, J., and Šlanhof, J. (2019). Comparison of Adhesive Properties of Polyurethane Adhesive System and wood-plastic Composites with Different Polymers after Mechanical, Chemical and Physical Surface Treatment. Polymers 11 (397), 397. doi:10.3390/polym11030397

Nguyen, T. P., Chen, W., Cao, Y., Wang, X., Shi, S., Chen, M., et al. (2018). Improving Bonding Strength of Oven-dried Poplar Veneers Using Atmospheric Cold Plasma Treatment. Biores. 13 (1), 1843-1851. doi:10.15376/biores.13.1.1843-1851

Peng, X., and Zhang, Z. (2018). Plasma Treatment of Plastic Film or Decorative Veneer and its Effects on the Peel Strength and Curling Deformation of Plastic Film-Reinforced Pliable Decorative Sliced Veneer (PR-RP-DSV). Holzforschung 73 (3), 313-322. doi:10.1515/hf-2018-0084

Peng, X., and Zhang, Z. (2019). Surface Properties of Different Natural Precious Decorative Veneers by Plasma Modification. Eur. J. Wood Prod. 77, 125-137. doi:10.1007/s00107-018-1355-3

Peters, F., Hünnekens, B., Wieneke, S., Militz, H., Ohms, G., and Viöl, W. (2017). Comparison of Three Dielectric Barrier Discharges Regarding Their Physical Characteristics and Influence on the Adhesion Properties on maple, High Density Fiberboards and wood Plastic Composite. J. Phys. D: Appl. Phys. 50, 475206. doi:10.1088/1361-6463/aa8fad

Recek, N. (2019). Biocompatibility of Plasma-Treated Polymeric Implants. Materials (Basel). 12 (2), 240. doi:10.3390/ma12020240

Sauerbier, P., Anderson, J., and Gardner, D. (2018). Surface Preparation and Treatment for Large-Scale 3D-Printed Composite Tooling Coating Adhesion. Coatings 8 (457), 457. doi:10.3390/coatings8120457

Soriano, J., Pellis, B. P., and Mascia, N. T. (2016). Mechanical Performance of Glued-Laminated Timber Beams Symmetrically Reinforced with Steel Bars. Compos. Structures 150, 200-207. doi:10.1016/j.compstruct.2016.05.016

Steiger, R., Gehri, E., and Widmann, R. (2006). Pull-out Strength of Axially Loaded Steel Rods Bonded in Glulam Parallel to the Grain. Mater. Struct. 40, 69-78. doi:10.1617/s11527-006-9111-2

Talviste, R., Galmiz, O., Stupavská, M., Tučeková, Z., Kaarna, K., and Kováčik, D. (2019). Effect of DCSBD Plasma Treatment on Surface Properties of Thermally Modified wood. Surf. Inter. 16, 8-14. doi:10.1016/j.surfin.2019.04.005

Tang, S., Kwon, O.-J., Lu, N., and Choi, H.-S. (2005). Surface characteristics of AISI 304L Stainless Steel after an Atmospheric Pressure Plasma Treatment. Surf. Coat. Technology 195, 298-306. doi:10.1016/j.surfcoat.2004.07.071

Tang, S., Lu, N., Myung, S.-W., and Choi, H.-S. (2006). Enhancement of Adhesion Strength between Two AISI 316 L Stainless Steel Plates through Atmospheric
Pressure Plasma Treatment. Surf. Coat. Technology 200, 5220-5228. doi:10.1016/j.surfcoat.2005.06.020

Tlustochowicz, G., Serrano, E., and Steiger, R. (2011). State-of-the-art Review on Timber Connections with Glued-In Steel Rods. Mater. Struct. 44, 997-1020. doi:10.1617/s11527-010-9682-9

Uzel, M., Togay, A., Anil, Ö., and Söğütlü, C. (2018). Experimental Investigation of Flexural Behavior of Glulam Beams Reinforced with Different Bonding Surface Materials. Construction Building Mater. 158, 149-163. doi:10.1016/ j.conbuildmat.2017.10.033

Wagner, H.-E., Brandenburg, R., Kozlov, K. V., Sonnenfeld, A., Michel, P., and Behnke, J. F. (2003). The Barrier Discharge: Basic Properties and Applications to Surface Treatment. Vacuum 71, 417-436. doi:10.1016/S0042-207X(02)00765-0

Williams, T. S., Yu, H., Yeh, P.-C., Yang, J.-M., and Hicks, R. F. (2014). Atmospheric Pressure Plasma Effects on the Adhesive Bonding Properties of Stainless Steel and Epoxy Composites. J. Compos. Mater. 48 (2), 219-233. doi:10.1177/0021998312470150

Zhang, W., Cao, Y., Yang, P., Chen, M., and Zhou, X. (2019). Manufacturing and Interfacial Bonding Behavior of Plasma-Treated-Carbon Fiber Reinforced Veneer-Based Composites. Compos. Structures 226, 111203. doi:10.1016/ j.compstruct.2019.111203

Zhang, W., Yang, P., Cao, Y., Yu, P., Chen, M., and Zhou, X. (2020). Evaluation of Fiber Surface Modification via Air Plasma on the Interfacial Behavior of Glass Fiber Reinforced Laminated Veneer Lumber Composites. Construction Building Mater. 233 (117315), 117315. doi:10.1016/j.conbuildmat.2019.117315

Žigon, J., Kovač, J., Zaplotnik, R., Saražin, J., Šernek, M., Petrič, M., et al. (2020). Enhancement of Strength of Adhesive Bond between wood and Metal Using Atmospheric Plasma Treatment. Cellulose 27, 6411-6424. doi:10.1007/s10570020-03212-8

Žigon, J., Petrič, M., and Dahle, S. (2018). Dielectric Barrier Discharge (DBD) Plasma Pretreatment of Lignocellulosic Materials in Air at Atmospheric Pressure for Their Improved Wettability: A Literature Review. Holzforschung 72 (11), 979-991. doi:10.1515/hf-2017-0207

Conflict of Interest: The authors declare that the research was conducted in the absence of any commercial or financial relationships that could be construed as a potential conflict of interest.

Publisher's Note: All claims expressed in this article are solely those of the authors and do not necessarily represent those of their affiliated organizations, or those of the publisher, the editors and the reviewers. Any product that may be evaluated in this article, or claim that may be made by its manufacturer, is not guaranteed or endorsed by the publisher.

Copyright $\odot 2022$ Dahle, Srinivasa, Žigon, Cheumani Yona, Avramidis, Viöl and Petrič. This is an open-access article distributed under the terms of the Creative Commons Attribution License (CC BY). The use, distribution or reproduction in other forums is permitted, provided the original author(s) and the copyright owner $(s)$ are credited and that the original publication in this journal is cited, in accordance with accepted academic practice. No use, distribution or reproduction is permitted which does not comply with these terms. 